\title{
Wacana Kapitalisme Omnibus Law Cipta Kerja
}

\section{Olih Solihin ${ }^{*}$, Anur Janah}

${ }^{1}$ Program Studi Ilmu Komunikasi, FISIP Universitas Komputer Indonesia, Bandung, Indonesia

*Email Korespondensi: olih.solihin@email.unikom.ac.id

Kata kunci: omnibus law, analisis wacana kritis, kapitalisme, pikiran
Keyword: omnibus law, analysis critical discourse, capitalism, pikiran

\section{A B S T R A K}

Penelitian ini bertujuan untuk mengetahui wacana kapitalisme omnibus law dari berita Harian Pikiran Rakyat yang menyebut omnibus law jangan sampai kapitalis pada 17 Februari 2020. Pendekatan penelitian kualitatif adalah dengan menggunakan metode analisis wacana critical design norman Fairclough. Peneliti memperoleh informan dalam penelitian ini sebanyak empat orang dengan menggunakan teknik metode purposive sampling. Pengumpulan data adalah wawancara mendalam, dokumentasi, studi pustaka, dan data online. Teknik analisis data yang digunakan adalah pengumpulan data, reduksi data, penyajian data, dan penarikan kesimpulan. Sedangkan data uji coba dirusak adalah untuk menambah teman dengan ketekunan dan diskusi Anda. Hasil kajian wacana kapitalisme omnibus law dari pemberitaan Harian Pikiran Rakyat yang bertajuk "omnibus law jangan sampai kapitalis" pada 17 Februari 2020, terbagi menjadi tiga bagian Norman Fairclough. Berdasarkan analisis desain pertama, dari segi teks omnibus law tidak kapitalisasi dijabarkan dengan, kata kalimat dan diksi informal juga denotatif atau memberikan tujuan yang jelas tanpa menyembunyikan makna. Kapitalisme dalam pemberitaan baik, dalam hal wacana wartawan yang menulis berita ini memiliki khusus mengenai isu omnibus, hukum sesama anggota wartawan dengan kita atau tidak berjalan dengan redaktur interaktif dan komunikatif dan dari praktek kerja atau rutinitas rapat redaksi terjadi atau agenda media pertemuannya dengan beberapa tahapan. Agenda pengaturan media, ketiga dari segi praktik sosiokulturalnya dalam pemberitaan seputar omnibus law tidak kapitalis yang diposting RUU omnibus law yang telah datang ke parlemen akan membahas hal ini meskipun tentangan dari masyarakat kepada wartawan memiliki masalah kelembagaan yang bertentangan dengan omnibus law oleh pemerintah.

\section{A B S TRA C T}

This study aims to know the discourse capitalism of an omnibus law from Pikiran Rakyat daily news who called an omnibus law do not to capitalist on February 17, 2020. The qualitative research approach is by using the method of analysis discourse critical design norman Fairclough. The researchers had obtained informants in this research as many as four persons using a technique purposive sampling method. The data collection is an in-depth interview, documentation, literature study, and online data. The data analysis technique used is data collection, data reduction, presentation of data, and the withdrawal of conclusion. While test data tampered with is to increase friend by your perseverance and discussion.The results of the study discourse capitalism of an omnibus law from Pikiran Rakyat daily news who called an "omnibus law do not to capitalist" on February 17, 2020, divides into three parts Norman Fairclough. Based on analysis of the design first, in terms of the text of the omnibus law not to capitalist elaborated with, said the sentence and diction informal also denotative or give clear objectives without concealment meaning. Capitalism in the news both, in terms of the discourse journalist who wrote this news having special concerning the issue of an omnibus, law a fellow member of the reporters with us or do not walk with an interactive editor and communicative and from work practices or routine editorial meeting occurred or agenda media his meeting with several stages. Media setting the agenda, third in terms of its sociocultural practices in the circumstantial news of an omnibus law not to capitalist posted the draft bill omnibus law ave come into the parliament will be discussing this is despite the opposition from the community to the journalist having the institutional issues at odds with omnibus law by the government.
PENDAHULUAN
Wacana kapitalisme bukanlah hal baru di Indonesia, peran negara dalam bentuk 
pemilikan dan penumpukan kapital berawal pada tahun 1950-an ketika perusahaanperusahaan negara didirikan sebagai reaksi terhadap nasionalisasi perusahaanperusahaan milik Belanda. Namun, dominasi perusahaan negara berakhir setelah kegagalan revolusi 1965 (Hill dalam Hiariej, 2006: 94). Media massa mempunyai keterikatan dengan sistem kapitalisme yaitu sebagai institusi kapitalis yang berorientasi pada keuntungan dan akumulasi modal. Ketika modal mengepung media massa, kalangan industri ini lebih menyerupai "pedagang", memanfaatkan kepemilikan saham atau modal untuk mengontrol isi media. Seperti halnya yang terjadi pada beberapa media di Indonesia di antaranya, Harian Umum Pikiran Rakyat, Tribun Jabar, dan Media Indonesia saat menanggapi isu Omnibus Law RUU Cipta kerja dalam kurun waktu bulan Februari 2020.

Masing-masing media membuat berita mengenai rangkaian peristiwa selama pembahasan Omnibus Law RUU Cipta kerja dengan tujuan serupa guna akumulasi modal, yang menjadi pembeda ialah pada bagaimana setiap berita dikemas sedemikian rupa agar terlihat menarik oleh pembaca melalui pemilihan diksi dan sudut pandang isu.

Harian Umum Pikiran Rakyat memuat isu Omnibus Law RUU Cipta kerja dengan judul berita "Omnibus Law Jangan Untuk Para Kapitalis", menampilkan Omnibus Law sebagai konsep hukum yang digunakan pemerintah untuk menyederhanakan peraturan regulasi terkait sektor ekonomi investasi tetapi justru mengenyampingkan hak-hak buruh. Berita tersebut juga merupakan bentuk sindiran bahwa Omnibus Law jangan sampai diperuntukkan bagi para kaum kapitalis atau para pemegang modal saja. Pada beberapa paragraf terdapat pengulangan kalimat tertentu sebagai bentuk penekanan bahwa isu Omnibus Law RUU Cipta kerja merupakan permasalahan serius.

Polemik lain Omnibus Law RUU Cipta kerja ialah landasan sosiologis penyusunan Omnibus Law RUU Cipta kerja terkesan dibuat-buat dan tidak menggambarkan kebutuhan masyarakat yang sebenarnya. Bahkan dapat disebut bahwa dalam pembentukan Omnibus Law RUU Cipta kerja kemungkinan besar terdapat perbedaan paradigma yaitu paradigma demi orang banyak atau demi kepentingan negara (Zainal Arifin Mochtar, 2020).

Paradigma demi orang banyak lebih mengutamakan hal-hal yang menjadi kebutuhan masyarakat sedangkan paradigma pemerintah dalam pembentukan Omnibus Law RUU Cipta kerja lebih kepada terciptanya pertumbuhan ekonomi yang cepat. Hal ini dapat dilihat dari berbagai pernyataan pemerintah yang menyebut bahwa Omnibus Law RUU Cipta kerja merupakan salah satu sarana mengharmonisasikan regulasi yang bertujuan memberikan kemudahan investasi di Indonesia dengan harapan dapat memberikan dampak positif pada meningkatnya investasi. Apabila dilihat dari sudut pandang pragmatisme, seharusnya produk hukum bertujuan untuk mewujudkan kepentingan masyarakat dan kesejahteraan sosial sehingga dalam penyusunannya haruslah didasarkan pada fakta empiris yang terjadi di masyarakat dan apa saja yang menjadi kebutuhan masyarakat. (Dewan mahasiswa justica Fakultas Hukum UGM, 2020).

Sementara itu, buruh dalam cakupan

Omnibus Law RUU Cipta kerja diperbincangkan hak maupun kesejahteraannya karena tak beriringan dengan perolehan keuntungan para investor, hal tersebut membuat buruh memiliki sisi menarik untuk menjadi komoditas bagi industri media. Seperti judul berita "Omnibus Law Jangan Untuk Para Kapitalis" yang dimuat oleh Harian Umum Pikiran Rakyat edisi 17 Februari 2020.

Berita "Omnibus Law Jangan Untuk Para Kapitalis" menempatkan buruh dikapitalisasi dengan mengeksploitasi hak serta kesejahteraannya melalui pembahasan singkat sejumlah undang-undang seperti pembahasan pasal 88 UUK 13/2003 mengenai upah dan pasal 78 UUK 13/2003 mengenai jam kerja. Harian Pikiran Rakyat juga membuat berita "RUU Omnibus Law diserahkan (sejumlah buruh menolak Omnibus Law Cipta kerja)" menampilkan buruh sebagai objek komodoti untuk menarik minat para pembaca dengan menggunakannya pada sub judul tetapi porsi yang ditampilkan untuk suara-suara buruh justru berada pada paragraf paling bawah. 
Pendekatan Fairclough menyatakan, wacana merupakan bentuk penting praktik sosial yang memproduksi dan mengubah pengetahuan, identitas dan hubungan sosial yang mencakup hubungan kekuasaan dan sekaligus dibentuk oleh struktur dan praktik sosial yang lain. Dalam Marianne W. Jorgensen dan Philips (2007:123), Fairclough memahami struktur sosial sebagai hubungan sosial di masyarakat secara keseluruhan dan di lembaga-lembaga khusus yang terdiri dari atas unsur-unsur kewacanaan dan non kewacanaan.

Pendekatan Fairclough merupakan bentuk wacana analisis yang berorientasi pada teks dan berusaha menyatukan tiga tradisi Marianne W. Jorgensen dan Philips (2007:123), yakni:

1. Analisis teksual yang terperinci di bidang linguistik (termasuk tata bahasa fungsional Michael Halliday).

2. Analisis makro-sosiologis parktik sosial (termasuk teori Fairclough, yang tidak menyediakan metodologi untuk menganalisis teks-teks khusus).

3. Tradisi interpretatif dan mikrososiologis dalam sosiologi (termasuk etmetodolgi dan analisis percakapan), kehidupan sehari-hari diperlakukan sebagai produk tindakan orang-orang.

Tindakan tersebut mengikuti sederet prosedur dan kaidah "akal sehat".

Untuk mengetahui Wacana Kapitalisme di dalam berita "Omnibus Law jangan Untuk Para kapitalis" yang dimuat oleh koran Harian Pikiran Rakyat edisi 17 Februari maka peneliti menggunakan desain analisis wacana kritis model Norman Fairclough dengan menggunakan tiga pembahasan yaitu analisis dari segi teks, analisis dari segi praktik wacana, dan analisis dari segi praktik sosiokultural.

Sejarah omnibus law adalah undangundang yang substansinya merevisi dan/atau mencabut banyak undang-undang. Konsep ini berkembang di negara- negara common law dengan sistem hukum anglo saxon seperti Amerika Serikat, Belgia, Inggris dan
Kanada. Konsep omnibus law menawarkan pembenahan permasalahan yang disebabkan karena peraturan yang terlalu banyak (over regulasi) dan tumpang tindih (overlapping). Bila permasalahan tersebut diselesaikan dengan cara biasa, maka akan memakan waktu yang cukup lama dan biaya yang tidak sedikit. Belum lagi proses perancangan dan pembentukan peraturan perundang-undangan seringkali menimbulkan deadlock atau tidak sesuai kepentingan.

Untuk mejelaskan masalah diatas, penulis mengarah pada penting atau tidaknya omnibus law melainkan menerka bentuk pemerintahan apabila omnibus law diterapkan di Indonesia. Pendapat menarik oleh Robert L. Nightingale bawa pembuatan undang-undang omnibus tergantung pada penggunaan satu kendaraan hukum, sebuah undang-undang yang diusulkan, diperdebatkan, diamandemen, dan disahkan untuk meloloskan sejumlah ketentuan. Dikatakan juga bahwa omnibus law sebagai "peraturan perundang-undangan yang membahas banyak hal, masalah, dan program yang tidak harus terkait, dan karenanya biasanya sangat kompleks dan panjang."5 Pendapat Robert L. Nightingale memiliki perbedaan konsep bahwa omnibus law biasanya "berisi satu RUU berbagai hal berbeda, biasanya dirancang sedemikian rupa untuk memaksa eksekutif baik untuk menerima semua ketentuan kecil yang tidak terkait atau untuk memveto ketentuan utama. " Menurut definisi, omnibus law menghasilkan kompromi.6 Perbandingan kedua ketika omnibus law sebagai penegakan hukum saja maka juga terait dengan demokrasi. Prinsip demokrasi mengandung arti dijunjung tingginya hak setiap orang untuk berpendapat, untuk memiliki ideologi tertentu, dan untuk memiliki identitas tertentu serta menghargai setiap pendapat yang keluar dari pikiran setiap orang. Konsep demokrasi menjadi sebuah kata kunci tersendiri dalam bidang ilmu politik. Prinsip semacam trias politica ini menjadi sangat penting untuk diperhitungkan ketika fakta-fakta sejarah mencatat kekuasaan pemerintah (eksekutif) yang begitu besar ternyata tidak mampu untuk membentuk masyarakat yang adil dan beradab, bahkan kekuasaan absolut pemerintah seringkali menimbulkan pelanggaran terhadap hak-hak asasi manusia. 
Dalam kajian hukum di Amerika, omnibus law dikenal dengan omnibus bill dan merupakan kebebasan dalam membentuk suatu peraturan dari legislatif. Para anggota bebas menentukan cara untuk menentukan suatu tujuan dan cara apapun bisa dilakukan agar cara tersebut tercapai. Namun permasalahannya apakah cara tersebut ilegal atau legal? Oleh karena itu pembatasan adalah hal yang wajib karena kebebasan dalam menentukan hukum akan memunculkan peraturan yang tidak sesuai dengan keadilan hukum. Pengadian persemakmuran Pennsylvania memberikan argumen menarik yaitu membentuk masyarakat yang adil dan beradab, bahkan kekuasaan absolut pemerintah seringkali menimbulkan pelanggaran terhadap hak-hak asasi manusia.

Penelitian ini membahas bentuk pemerintahan perspektif omnibus law. Dalam kajian hukum di Amerika, omnibus law dikenal dengan omnibus bill dan merupakan kebebasan dalam membentuk suatu peraturan dari legislatif. Para anggota bebas menentukan cara untuk menentukan suatu tujuan dan cara apapun bisa dilakukan agar cara tersebut tercapai. Namun permasalahannya apakah cara tersebut ilegal atau legal? Oleh karena itu pembatasan adalah hal yang wajib karena kebebasan dalam menentukan hukum akan memunculkan peraturan yang tidak sesuai dengan keadilan hukum. Pengadian persemakmuran Pennsylvania memberikan argumen menarik yaitu "Bills, popularly called omnibus bills, became a crying evil, not only from the confusion and distraction of the legislative mind by the jumbling together of incongruous subjects, but still more by the facility they afforded to corrupt combinations of minorities with different interests to force the passage of bills with provisions which could never succeed if they stood on their separate merits. So common was this practice that it got a popular name, universally understood, as logrolling. A still more objectionable practice grew up, of putting what is known as a rider (that is, a new and unrelated enactment or provision) on the appropriation bills, and thus coercing the executive to approve obnoxious legislation, or bring the wheels s logrolling. A still more objectionable practice grew up, of putting what is known as a rider (that is, a new and unrelated enactment or provision) on the appropriation bills, and thus coercing the executive to approve obnoxious legislation, or bring the wheels.

Adapun Tujuan yang ingin dicapai dalam penelitian ini adalah:

1. Untuk mengetahui Bagaimana "Omnibus Law RUU Cipta kerja" yang dimuat pada Harian Umum Pikiran Rakyat edisi 17 Februari 2020 digambarkan dari segi teks

2. Untuk mengetahui Bagaimana "Omnibus Law RUU Cipta kerja" yang dimuat pada Harian Umum Pikiran Rakyat edisi 17 Februari 2020 digambarkan dari segi praktik wacana.

3. Untuk mengetahui Bagaimana "Omnibus Law RUU Cipta kerja" yang dimuat pada Harian Umum Pikiran Rakyat edisi 17 Februari 2020 digambarkan dari segi praktik sosialkultural.

\section{METODE}

Analisis wacana kritis adalah sebuah upaya untuk mengungkapkan konstelasi kekuasaan yang terjadi dalam proses produksi dan reproduksi makna. Individu tidak dianggap sebagai subjek netral yang bisa menafsirkan sesuatu sesuai pikirannya, di balik penafsirannya terdapat kekuatan sosial dalam masyarakat yang mempengaruhinya. Analisis wacana kritis berangkat dari tradisi analisis wacana. Analisis wacana muncul sebagai reaksi terhadap ilmu linguistik murni yang tidak bisa mengungkap hakikat bahasa secara sempurna. Dalam hal ini, para pakar analisis wacana mencoba memberikan alternatif dalam memahami arti bahasa tersebut. Analisis wacana mengkaji bahasa secara terpadu, dalam arti tidak terpisah-pisah seperti dalam analisis linguitik. Semua unsur bahasa terikat pada konteks pemakaian. Analisis wacana kritis mengasumsikan bahwa bahasa bukanlah medium netral. Bahasa merupakan representasi dari strategi, wacana, maupun bentuk kekuasaan tertentu (Eriyanto, 2011:6).

Analisis wacana kritis ingin mengoreksi pandangan konstruktivisme yang kurang sensitif pada proses produksi dan 
reproduksi makna yang terjadi secara historis maupun institusional. Pandangan ini masih belum menganalisis faktor-faktor hubungan kekuasaan yang inheren dalam setiap wacana, yang pada gilirannya berperan dalam membentuk jenis-jenis subjek tertentu berikut perilaku-perilakunya (Eriyanto, 2011:6).

Analisis wacana tidak dipusatkan pada kebenaran atau ketidak benaran struktur tata bahasa atau proses penafsiran seperti pada analisis konstruktivisme, namun ia menekankan pada konstelasi kekuatan yang terjadi pada proses produksi dan reproduksi makna. Analisis wacana kritis dipakai untuk membongkar kuasa yang ada dalam setiap proses bahasa. Batasan apa yang diperkenankan jadi wacana, perspektif yang mesti dipakai, dan topik yang dibicarakan. Wacana tidak dipahami sebagai sebuah studi bahasa. Bahasa yang dianalisis di sini berbeda dengan studi bahasa dalam pengertian linguistik tradisional. Ia dianalisis bukan sekedar menggambarkan aspek kebahasaannya semata, tetapi dihubungkan dengan konteks.

Menurut Fairclough dan

Wodak, analisis wacana kritis melihat wacana (pemakaian bahasa dalam tuturan dan tulisan) sebagai bentuk dari praktik sosial. Menggambarkan wacana sebagai praktik sosial yang menyebabkan sebuah hubungan dialektis di antara peristiwa diskursif tertentu dengan situasi, institusi, dan struktur sosial yang membentuknya. Berikut beberapa karakteristik penting analisis wacana kritis dalam Marianne W. Jorgensen dan Philips pada Analisis Wacana Teori dan Metode (2007:115): 1).Tindakan Prinsip pertama, wacana dipahami sebagai sebuah tindakan. Dengan pemahaman seperti ini, ada beberapa konsekuensi bagaimana wacana harus dipandang. 2). Historis, salah satu aspek penting untuk bisa mengerti teks adalah dengan menempatkan wacana itu dalam konteks historis tertentu. Pemahaman mengenai teks ini hanya akan diperoleh kalau kita bisa memberikan konteks historis di mana teks itu diciptakan. Bagaimana situasi sosial politik pada saat itu. 3) Kekuasaan. Setiap wacana yang muncul baik dalam bentuk teks, percakapan, atau apa pun, tidak dipandang sebagai sesuatu yang alamiah, wajar, dan netral, tetapi merupakan bentuk pertarungan kekuasaan. Konsep kekuasaan adalah salah satu kunci hubungan antara wacana dengan masyarakat. 4) Ideologi. Penciptaan teks, percakapan, dan sejenisnya, dalam analisis wacana kritis, dianggap sebagai cerminan dari ideologi tertentu. Teori-teori klasik tentang ideologi di antaranya mengatakan, ideologi dibangun oleh kelompok yang dominan dengan tujuan untuk memproduksi dan melegitimasi dominasi mereka. Wacana dalam pedekatan semacam ini dipandang sebagai melalui medium mana kelompok dominan mempersuasi dan mengkomunikasikan kepada khalayak, produksi kekuasaan dan dominasi yang mereka miliki, sehingga tampak absah dan benar.

\section{HASIL PENELITIAN}

Analisis pada judul "Omnibus Law Jangan Untuk Para Kapitalis" Berita Harian Umum Pikiran Rakyat edisi 17 Februari 2020 berjudul "Omnibus Law Jangan Untuk Para Kapitalis". Pada judul berita koran Pikiran Rakyat ada kata "Omnibus Law" yang merupakan bentuk kata benda sejalan dengan makna juga arti dari kata tersebut yaitu untuk semua banyak, lalu disetarakan penambahan kata "Law" untuk mempertegas bahwa konteks yang dimaksud adalah sebuah produk hukum atau konsep untuk menyederhanakan Undang-undang. Penggunaan kata "Jangan" di sini ialah seruan atau larangan yang memiliki arti sebuah tindakan atau hal untuk menyatakan makna negatif agar tidak melakukan sesuatu. Sementara penggunaan kata "Untuk" ialah kata tugas yang jika dilihat kata setelahnya terdapat kata terakhir yaitu "Para Kapitalis" dengan makna para pelukan tindak kapitalisme dikhususkan untuk mendapatkan sebuah penegasan agar tidak mendapatkan keistimewaan atau keuntungan tersendiri dari Omnibus Law.

\section{- Analisis Lead}

Berita "omnibus Law jangan Untuk Para kapitalis" dibuat di Jakarta saat pewarta 
yang bertugas di gedung DPR RI turut Meliput diskusi mengenai omnibus Law Cipta kerja yang menghadirkan tiga narasumber salah satunya adalah margarito Kamis, tetapi proses editing dan publikasi terjadi di Bandung dengan sistem pengiriman berita redaksi melalui email. Draft berita dibuat pada 11 Februari 2020 dan dipublikasikan pada 17 Februari 2020 dengan distribusi koran di seluruh Jawa Barat dan secara online dengan cakupan Nasional. Berita tersebut dikonsumsi oleh pembaca Setia koran harian umum Pikiran Rakyat dan masyarakat secara heterogen.

$$
\text { Pada level lead wartawan }
$$

menggunakan lead deskriptif. Penggunaan deskriptif pada lead dapat terlihat dari kalimat yang disuguhkan oleh wartawan, di sana tertera bagaimana Omnibus Law masuk ke dalam Prolegnas yang digagas Jokowi pada periode 2019 hingga 2024 nanti. Wartawan harian umum Pikiran Rakyat Berusaha menjelaskan bahwa setelah terpilihnya Presiden Joko Widodo pada periode kedua Omnibus Law masuk ke dalam Salah satu program kerja yang bertujuan untuk menyederhanakan sejumlah peraturan perundang-undangan di Indonesia. Adapun beberapa aturan yang dimuat melalui konsep omnibus law ialah kita kerja, sistem perpajakan, farmasi, dan ibukota baru. Kalimat yang terdapat pada lead coba berusaha menegaskan dan menginformasikan kepada masyarakat bahwa untuk pertama kalinya Indonesia akan menerapkan konsep omnibus law secara resmi.

\section{- Isi Berita}

Pada berita yang dipublikasi oleh Harian Umum Pikiran Rakyat edisi 17 Februari 2020 dengan judul "Omnibus Law Jangan untuk Para Kapitalis" memuat isi statement salah seorang pakar hukum tata negara, Maragrito Kamis, dalam diskusi yang secara rutin diadakan di gedung DPR RI Senayan. Pada rangkaian paragraf tersebut di jelaskan bahwa presiden RI masa periode 20192024 yaitu Jokowi mengemukakan dalam pelantikannya sebagai presiden sebuah program kerja yang akan dilaksanakan dalam rezimnya yaitu Omnibus Law. Pada masyarakat Indonesia sendiri Omnibus Law adalah sebuah konsep baru dengan tujuan penyederhanaan sejumlah Undang-undang melalui pemangkasan pasal dan ayat untuk mempermudah pertumbuhan ekonomi Indonesia melalui jaminan hak bagi para investor asing. Tetapi, hal yang harus digaris bawahi adalah pembuatan Omnibus Law nyatanya tidak lepas dari kepentingan kelompok tertentu sehingga masyarakat sebagai pihak yang seharusnya disejahterakan melalui konsep hukum tersebut justru beralih menjadi korban khususnya kaum buruh. Maka, Margarito melalui statementnya menyatakan publik tidak boleh bodoh menerima alasan yang dibuat pemerintah mengenai Omnibus law karena sejatinya Omnibus Law adalah produk yang hanya akan menguntungkan kapitalis sehingga tak ada kesempatan bagi masyarakat untuk menikmati hak dan keuntungan yang sama dengan mereka para pemilik modal. Margrito juga beberapakali menyinggung seringnya pemerintah membuat dalih dalam menutupi hal yang sebenernya telah menjadi kecurigaan masyarakat pada proses pembentukan Omnibus Law yang bermasalah. Diakhir, Maragrito memiliki harapan agar jangan sampai ketika Rancangan undang-undang ini disahkan kemudian akan membuat para Kapitalis melenggang dengan tenang di atas penderitaan para buruh.

\section{- Koteks}

Berita ini dipilih karena menyorot pendapat ahli hukum yang secara terang-terangan memperingati bahaya dari penerapan Omnibus Law. Penulis berita ini adalah Muhammad Irfan dan Redaktur Politik Suhirlan Ardhityanto. Berita ini diterbitkan dalam rangka mengkawal isu Omnibus Law yang hangat diperbincangkan. Berita ini ditempatkan di rubrik politik pada halaman delapan.

\section{- Luaran Teks}

Layout satu kotak terdapat pada pojok kanan bawah. Judulnya "Omnibus Law Jangan Untuk Para Kapitalis". Berita ini terdiri dari 6 Paragraf dimulai dengan Jokowi yang akan mengesahkan Omnibus Law dan memasukanya kedalam Prolegnas, lalu alinea kedua adalah bagaimana sikap yang harusnya dimiliki publik dalam mengahadapi Omnibus Law, alinea tiga berisi pendapat Maragrito Kamis yang menyatakan Omnibus Law adalah cara kapitalis untuk menguasai kekayaan, alinea empat adalah contoh kasus 
dari Omnibus Law Cipta kerja yaitu jam kerja buruh yang semakin sedikit namun tak berimbang pada upah, alinea lima adalah pendapat Maragrito Kamis mengenai cara Kapitalis mengumpulkan profit dan alinea terkahir berupa harapan Maragrito sekaligus penulis agar masyarakat bisa lebih kritis dalam menghadapi Omnibus Law.

\section{- Sarana Retorika}

Teks laporan ini dibangun saat draft RUU Cipta Kerja sudah diserahkan pada DPR RI untuk kemudian dikaji, namun terdapat ketimpangan pendapatan saat publik khususnya buruh tak ikut serta dalam pengkajiannya.. Implikasinya proses pengkajian dan penerapan Omnibus Law di Indonesia menyita polemik karena konsep hukum ini tidak bisa mengimbangi kepentingan berbagai pihak. Idiom, "Jangan sampai Udang-udang ini mengulang sejarah UU Kapitalis" "Cara kapitalis mengadali" "Publik tidak benar-benar bodoh". Aktor, Jokowi (Presiden RI 2019-2024), Ma'ruf Amin (Wakil Presiden RI 2019-2024), Margarito Kamis (Ahli hukum tata negara), Pemerintah, Publik (Pembaca/masyarakat umum). Acuan yang dipakai Rancangan Undang-undang mengenai Jam kerja Buruh, upah dan sejarah kelam Indonesia sama kapitalisasi rezim Soeharto.

\section{- Isi dan pernyataan Ideologis}

Konsep yang ditampilkan teks ini adalah, Margarito berusaha memberi tahu bahwa Omnibus Law bukan hanya sekedar produk hukum namun menyimpan banyak kepentingan di dalamnya.

Teks ini juga memperlihatkan kata jangan mengulang sekarang dan UU Kapitalis yang merujuk pada rezim keprisedanan Seoharto.

\section{- Kekhasan artikel}

Membahas mengenai sebuah hal baru di masyarakat namun tetap dengan isu lama yaitu konsep Omnibus Law dan sistem kapitlias.

Bahasa yang digunakan semibaku dengan tujuan agar mudah dipahami pembaca. Jenis berita ini masuk ke dalam straightnews atau hardnews.

\section{- Posisi wacana}

Isu ini merupakan berita straight news yang berada pada halaman politik dan sedang hangat diperbincangkan. Posisi wacana ini cukup ringkas dan namun tak diikuti berita lain dalam edisi yang sama.

\section{KESIMPULAN}

Pada berita yang dipublikasi oleh koran harian umum Pikiran Rakyat dengan judul "Omnibus Law Jangan Untuk Para kapitalis" edisi 17 Februari 2020 memiliki enam alinea dan memiliki jenis berita Straight news serta gaya bahasa yang semi baku. Melalui penjelasan singkat yang dipaparkan dalam berita tersebut, pewarta menekankan pendapat margarito Kamis yang juga mencerminkan kesetujuannya, bahwa Omnimbus Law Cipta kerja bukanlah merupakan murni produk hukum melainkan terdapat pihak yang menungganginya dengan kepentingan tertentu.

Pemerintah seringkali menyatakan bahwa Omnimbus Law digunakan untuk mempermudah investasi asing ke Indonesia dan memperkuat perekonomian negara, tetapi kenyataannya pemerintah hanya memberikan akses istimewa pada para investor asing untuk mengambil keuntungan sebanyakbanyaknya dari Indonesia dan kurang maksimal dalam mementingkan nasib buruh yang menjadi korban langsung dari penerapan Omnimbus Law

\section{Reference}

Busroh, Firman Freaddy, Konseptualisasi Omnibus Law dalam Menyelesaikan Permasalahan Regulasi Pertanahan, ARENA HUKUM Volume 10, Nomor 2, Agustus 2017

Glen S. Krutz, Tactical Manuevering on Omnibus Bills in Congress, American Journal of Political Science, Vol 45, No 1 (January 2001).

Kurt Taylor Gaubatz, Kant, Democracy And History, Journal of Democracy Volume 7 Number 4 October 1996.

Massicotte, Omnibus Bills in Theory and Practice, Canadian Parliamentary Review/Spring 2013.

McCabe, Margaret Sova (2018) "Cooperation or Compromise? Understanding the Farm Billas Omnibus Legislation," Journal of Food Law \& Policy: Vol. 14 : No. 1 , Article 5.

Tara Leigh Grove, Symposium Foreword: Some Puzzles Of State Standing, Notre Dame Law Review, Vol. 94:5.

Waldemar Hanasz, Poetic Justice For Plato's 
Komunika: Jurnal Ilmu Komunikasi

Democarcy?, Interpretation: A Journal of 